\title{
TECHNICAL NOTE: ON THE CORRECTNESS OF LOAD LOSS FACTOR
}

\author{
A. 0. Ekwue* \\ JACOBS ENGINEERING INC/BRUNEL UNIVERSITY LONDON, UNITED KINGDOM \\ Email address. arthur.ekwue@brunel.ac.uk
}

\begin{abstract}
Load Loss Factor (LLF) is a function of the estimate of the losses between the grid supply point and the consumers. It varies with voltage levels and types of consumers (such as domestic, industrial or commercial). This technical note compares the accuracy of LLF derived from exact daily and seasonal variation in demand and estimated values from the system load factor (LF).
\end{abstract}

Keywords: technical losses, load factor, load loss factor

\section{INTRODUCTION}

The procedure adopted to calculate the present annual (technical) energy (MWh) losses on any distribution network involves estimating the active power (MW) losses during peak demand period, separated into Fixed and Variable losses and then, by reference to the distribution network's demand characteristics, i.e. the daily and seasonal variation in demand, to estimate associated, annual energy losses.

The conversion of Variable losses during periods of peak demand into estimated associated annual energy losses is usually undertaken by determining the system LLF, either from a direct knowledge of the demand characteristics or more commonly by estimating the LLF based on the system Load Factor, i.e. the ratio of average demand to peak demand, and using this ratio to determine an approximation to the LLF via an empirical relationship.

The objective of this Technical Note is to compare the accuracy of LLF results derived by exact and approximate methods.

\section{CALCULATION METHODS}

\subsection{Exact Technique}

The exact LLF is derived from the formula:

$$
\mathrm{LLF}=\frac{\sum_{i=1}^{i=8760} \text { Hourly demand }(i)^{2}}{\text { Maximum Demand }{ }^{2} \times 8760}
$$

with 365 days in a year and 24 hours daily results in 8,760 hours annually.

This technique assumes that the hourly demand data for the entire year is available from the Distribution
Network Control Centre. For the Middle-East based distribution network case under study, it was possible to accurately determine the LLF for the years: 2009 to 2013.

\subsection{Approximate Technique}

LLF is related to Annual Load Factor (LF) as [1]:

LLF $=\alpha *$ Annual Load Factor $+(1-\alpha) *$ (Annual Load Factor) ${ }^{2}$

The range of $\alpha$ is between 0.15 and 0.30 for distribution networks [1] and the authors in [2] explain that the value of $\alpha$ depends on type and class of consumer.

\section{RESULTS}

A comparison of the results of the two methods is presented in Table 1. Based on the Annual Load Factor (LF) for the distribution network, Table 1 shows:

Exact calculation of LLF (i.e. Method 1) for years 2009 to 2013 based on equation (1).

Approximate calculation of LLF using $\alpha=0.3$ (i.e. Method 2a) for the same period and the error \% when compared with Method 1; the error in LLF varies from $9.5 \%$ to $12 \%$.

Approximate calculation of LLF using $\alpha=0.15$ (i.e. Method 2b) for the same period and the error \% when compared with Method 1; the error in LLF varies from $-1.4 \%$ to $0.8 \%$.Figure 1 shows a comparison of the Methods. Though the pattern of the graphs is similar, Method 2b follows Method 1 more closely than Method 2a. 
Table 1: Comparison of LLFS

\begin{tabular}{|l|c|c|c|c|c|}
\hline Year & $\mathbf{2 0 0 9}$ & $\mathbf{2 0 1 0}$ & $\mathbf{2 0 1 1}$ & $\mathbf{2 0 1 2}$ & $\mathbf{2 0 1 3}$ \\
\hline Annual Load Factor (LF) & 0.533 & 0.536 & 0.557 & 0.56 & 0.58 \\
\hline Annual Loss Load Factor (LLF) - Method 1 & 0.326 & 0.323 & 0.351 & 0.348 & 0.37 \\
\hline $\begin{array}{l}\text { Annual Loss Load Factor (LLF) - Method 2(a), } \alpha= \\
\begin{array}{l}0.3 \\
\text { Percentage error }\end{array}\end{array}$ & 0.359 & 0.362 & 0.384 & 0.388 & 0.409 \\
\cline { 2 - 6 } & 10 & 12 & 9.5 & 11.4 & 10.7 \\
\hline $\begin{array}{l}\text { Annual Loss Load Factor (LLF) - Method 2(b) } \\
\begin{array}{l}\alpha=0.15 \\
\text { Percentage error }\end{array}\end{array}$ & 0.321 & 0.325 & 0.347 & 0.351 & 0.373 \\
\hline Exact calculation of $\alpha$ & -1.4 & 0.5 & -1.1 & 0.7 & 0.8 \\
\hline
\end{tabular}

Exact calculation of $\alpha$ for the same period. This is determined from equation (2) as:

$\alpha=\left(\mathrm{LLF}-\mathrm{LF}^{2}\right) /\left(\mathrm{LF}-\mathrm{LF}^{2}\right)$

using the exact values of LLF determined from Method 1. For this specific distribution network, the values of $\alpha$ vary from 0.14 to 0.17 (average of 0.15 ).

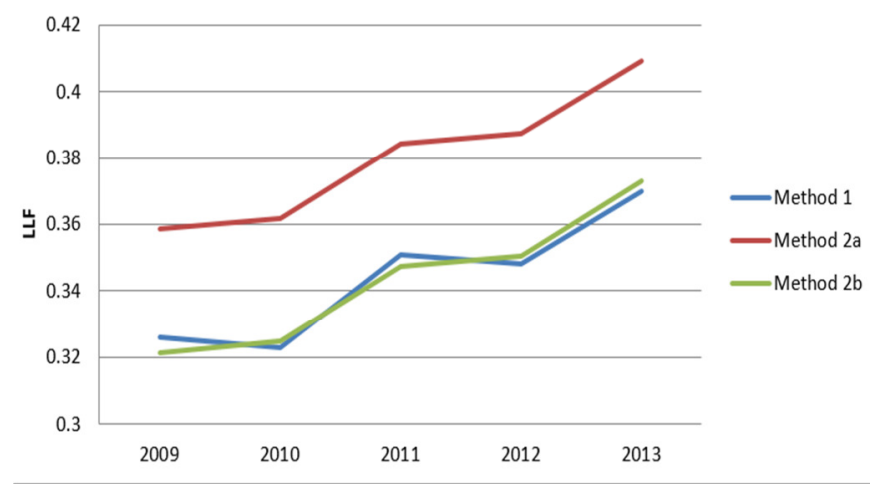

Figure 1: Plot of LLF against Year

\section{CONCLUSIONS}

A comparison of the LLF exact and approximate methods shows that it is difficult to know the realistic $\alpha$ to use in practical distribution networks. It is shown that the range of $\alpha$ appropriate for this network is 0.14 to 0.17 with an average of 0.15 ; this confirms the range of 0.15 to 0.3 suggested in [1] as applicable to most distribution networks. As the approximate method introduces some level of uncertainty, it is best to use the actual hourly demand data from the Distribution Network Control Centre, if available, in calculating the LLF. This will ensure a better evaluation of the technical losses in any distribution network.

\section{ACKNOWLEDGEMENT}

The author is grateful to his colleague, David Bailey, for the discussions on this subject.

\section{REFERENCES}

[1] Yusoff, M., Busrah A., Mohamad M and Au M. "A Simplified Approach in Estimating Technical Losses in TNB Distribution Network Based on Load Profile and Feeder Characteristics", Journal of Recent Advances in Management, Marketing and Finances, 2012, pp 99-105

[2] Pande, S. and Ghodekar, J.G. "Computation of Technical Power Loss of Feeders and Transformers in Distribution System using Load Factor and Load Loss Factor", Journal of Multidisciplinary Sciences \& Engineering, vol. 3, no. 6, 2012, pp 22-25 